\title{
(-) antax \\ Asthmatic adult with marked blood eosinophilia: is it truly asthma?
}

\author{
Shera Tan, ${ }^{1}$ Angela Takano, ${ }^{2}$ Aloysius Ho, ${ }^{3}$ Keng Leong $\operatorname{Tan}^{1}$
}

${ }^{1}$ Respiratory and Critical Care Medicine, Singapore General Hospital, Singapore ${ }^{2}$ Department of Pathology, Singapore General Hospital, Singapore

${ }^{3}$ Department of Hematology, Singapore General Hospital, Singapore

\section{Correspondence to} Dr Shera Tan,

shera_TAN@ttsh.com.sg

Accepted 21 March 2018

Check for updates

To cite: Tan S, Takano A Ho A, et al. BMJ Case Rep Published Online First: [please include Day Month Year]. doi:10.1136/bcr-2017 222344

\section{SUMMARY}

A middle-aged woman presented with symptoms suggestive of allergic asthma but with markedly elevated peripheral eosinophilia. She did not respond to inhaled corticosteroids, thereby prompting further investigations. Chest radiograph was normal. CT of the chest revealed bi-apical ground glass opacities. Bronchoalveolar lavage revealed predominantly eosinophilic yield. Autoimmune screen was negative. Bone marrow biopsy showed a normocellular marrow with increased eosinophils. A diagnosis of chronic eosinophilic pneumonia (CEP) was made after exclusion of other causes of eosinophilia. Treatment of her CEP with systemic corticosteroids (prednisolone $0.5 \mathrm{mg} / \mathrm{kg} /$ day) resulted in dramatic improvement in symptoms and peripheral eosinophilia.

\section{BACKGROUND}

Peripheral blood eosinophilia is frequently encountered in the general medical and respiratory clinics. Asthma is often associated with peripheral eosinophilia, however, marked levels of eosinophilia are uncommon and should warrant further investigation. The patient described in this article presented with an initial diagnosis of allergic asthma but failed to respond to inhaled corticosteroids. Marked blood eosinophilia prompted the investigation for other eosinophilic lung diseases, which eventually yielded a diagnosis of chronic eosinophilic pneumonia (CEP). This article illustrates the importance of a high index of suspicion for eosinophilic lung diseases should patients previously diagnosed as allergic asthma fail to respond to therapy, especially if this was associated with marked blood eosinophilia.

\section{CASE PRESENTATION}

A 47-year-old woman who was a lifelong non-smoker was referred to the pulmonary clinic for non-productive cough and exertional dyspnoea for the past 6 months. She worked as a manager in a trading company. Her medical, social, family, medication and travel histories were non-contributory. She had initially consulted another institution for similar symptoms 6 months prior. Full blood count (FBC) then showed mildly raised absolute eosinophil count of $0.98 \times 10^{9} / \mathrm{L}$ (differential eosinophil count $13.6 \%$ ). Chest radiograph was normal (figure 1A). Spirometry was normal with no bronchodilator response and the flow-volume loops were also normal. She did not have symptoms of allergic rhinitis or gastro-oesophageal reflux disease or atopy. She was treated for possible asthma with budesonide $160 \mu \mathrm{g}$ and formoterol $4.5 \mu \mathrm{g}$ combination turbuhaler, two puffs twice daily. In view of her lack of response to treatment, she was referred for further evaluation at our centre. Further history obtained during her visit to our clinic revealed that she had no fever, weight loss or night sweats. Clinical examination showed no clubbing or cervical lymphadenopathy.

\section{INVESTIGATIONS}

Repeat FBC count showed markedly raised absolute eosinophil count of $9.38 \times 10^{9} / \mathrm{L}$ (differential eosinophil count $56.6 \%$ ). A repeat chest radiograph was normal (figure 1B). Autoimmune workup including antidouble-stranded DNA antibody, extractable nuclear antigens (ENA) screen, rheumatoid factor, antineutrophil cytoplasmic antibody and antinuclear antibody was negative. Stool examination for ova, cysts, parasites, leukocytes and culture was also negative. Contrasted CT scan of the chest (figure 2A) showed ground glass changes with thickening of the interlobular septa at the apices of both lungs, more marked over the apical segment of the left upper lobe. These changes were notably absent in other parts of the lung (figure 2B-D). Bronchoalveolar lavage (BAL) with differential cell counts was performed from bilateral upper lobe apicoposterior segments, revealing predominantly eosinophilic yield of $83.3 \%$ (figure 3 , table 1 ). Bacterial, fungal and tuberculosis cultures from the BAL were negative. Transbronchial lung biopsy performed in the left upper lobe apicoposterior segment showed large collections of eosinophils predominantly in the interstitium and within the lumens of vessels (figure 4A,B). Specifically, allergic granulomas suggestive of granulomatosis with polyangiitis, typically consisting of histiocytes and multinucleated giant cells surrounding a central necrotic zone, was absent. A bone marrow biopsy was also performed which showed normal cellularity for age, approximately 50\%. Lymphocytes (about 10\%) showed normal morphology and feature a diffuse interstitial infiltrate of mainly singly disposed CD3 + Tcells, accompanied by occasional CD20+ B cells. A reactive lymphoid aggregate was present. Myeloid cell maturation was normal and no significantly increased numbers of immature myeloid precursors were seen $(<2 \%)$ despite immunostaining for CD34 and CD117. The FIP1L1-PDGFR- alpha fusion and Bcr-Abl transcripts were not detected in the bone marrow. These findings were in keeping with a normocellular marrow with increased eosinophils 


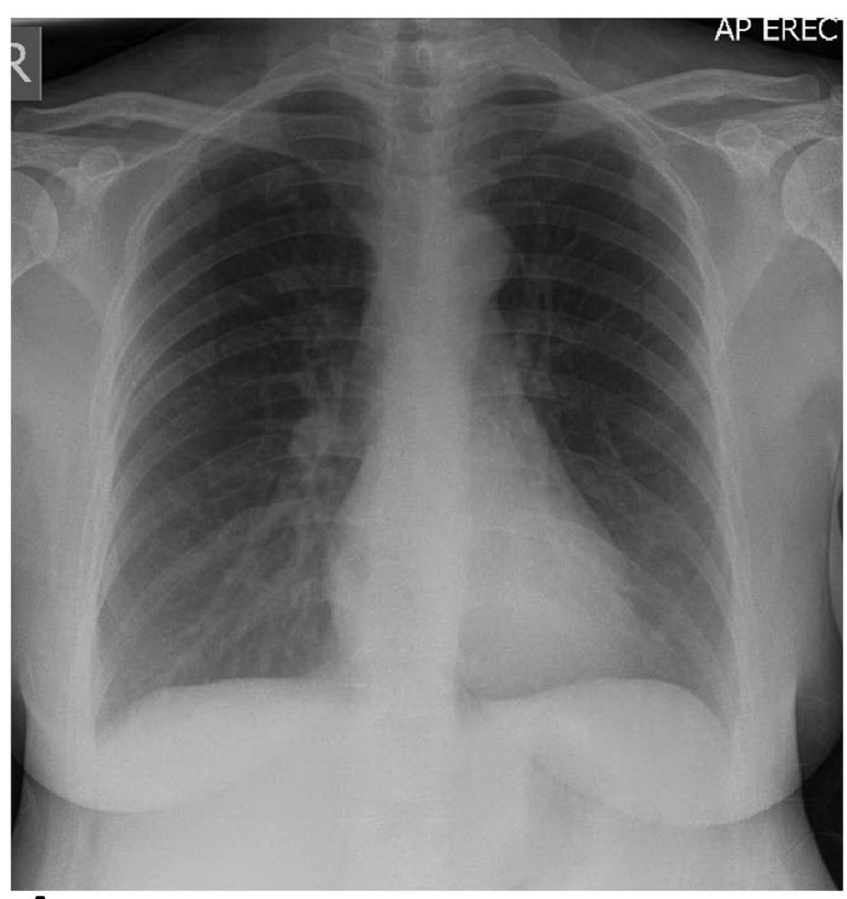

A

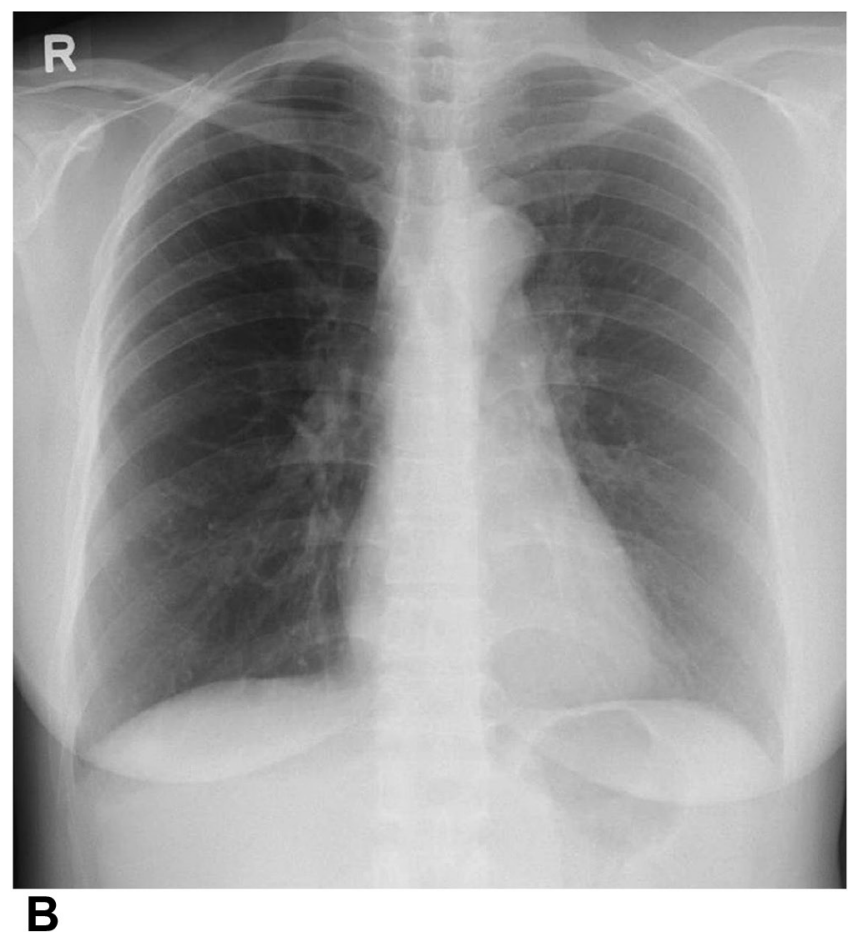

Figure 1 (A) Chest radiograph at time of initial presentation. (B) Chest radiograph 6 months later.

but without evidence of chronic myeloproliferative disorders or lymphomatous involvement. Flow cytometry was normal.

\section{DIFFERENTIAL DIAGNOSIS}

Possible differential diagnosis can be divided into two groups: primary causes of blood eosinophilia ad secondary causes of blood eosinophilia.

Primary causes of blood eosinophilia include:

1. Haematological malignancies (such as acute leukaemia or a chronic myeloid disorder).

2. Idiopathic hypereosinophilia.
Secondary causes of blood eosinophilia include:

1. Parasitic infections (such as schistosomiasis, visceral toxocariasis, stronglyloidiasis and paragonimiasis).

2. Allergy-related causes such as allergic asthma.

3. Autoimmune conditions (such as eosinophilic granulomatosis with polyangiitis, granulomatosis with polyangiitis, sarcoidosis and chronic eosinophilic pneumonia).

4. Drug-related causes (such as carbamazepine, sulfa drugs, non-steroidal anti-inflammatory drugs, nitrofurantoin, etc).

5. Malignancy (such as lymphoma, metastatic cancers).

In this patient, bone marrow biopsy and flow cytometry excluded myeloproliferative, lymphoproliferative disorders and malignancy. Extensive history obtained excluded drug-induced causes of peripheral eosinophilia. Several stool investigations, autoimmune screening tests and lack of systemic manifestations of autoimmune diseases also excluded parasitic and autoimmune causes. Investigations to exclude fungal infections such as coccidioidomycosis or parasitic infections (eg, Strongyloides antibody) should be considered in the appropriate endemic areas or in the presence of relevant travel history. Aspergillus antibody should be considered when clinical features of allergic bronchopulmonary aspergillosis is present (eg, mucus plugging, eosinophilia, elevated serum total $\operatorname{IgE}$ ).

A diagnosis of CEP was made due to the presence of respiratory symptoms, BAL eosinophilia with consistent imaging findings and exclusion of other known causes of eosinophilia as above.

\section{TREATMENT}

Our patient was started on oral prednisolone $30 \mathrm{mg}$ daily after the diagnosis of CEP was made. Repeat FBC after 2 weeks of starting steroid therapy showed a dramatic decrease in peripheral blood eosinophilia. The absolute eosinophil count decreased from $9.38 \times 10^{9} / \mathrm{L}(56.6 \%)$ to $1.07 \times 10^{9} / \mathrm{L}(13.5 \%)$. Her symptoms of cough and breathlessness had also improved.

\section{OUTCOME AND FOLLOW-UP}

Following initial steroid therapy at $0.5 \mathrm{mg} / \mathrm{kg} / \mathrm{day}$, our patient continued to improve, and the steroid dose was tailed down over the course of a year. However, she did have occasional relapses with worsened exertional dyspnoea and required uptitration of steroid doses each time.

\section{DISCUSSION}

The concurrent appearance of blood eosinophilia and pneumonic lung infiltration is described as pulmonary eosinophilia or pulmonary infiltration with eosinophils syndrome. The defining characteristics of pulmonary eosinophilia include: peripheral blood eosinophilia with abnormalities on pulmonary imaging, lung tissue eosinophilia and increased eosinophils in BAL fluid. ${ }^{1-3}$

CEP was first described by Carrington in 1969, where he described nine patients who presented with a syndrome of chronic and life-threatening illness with high fever, night sweats, weight loss and severe dyspnoea. ${ }^{4}$ It is a rare disorder with a reported incidence of 0.23 per 100000 population per year between 1990 and $2004^{1}$ and account for up to $2.5 \%$ of all interstitial lung disease cases in Europe. ${ }^{2}$ The cause of CEP is currently unknown but may involve selective migration of T-helper 2 cells to the lungs and release of interleukin 5 and related cytokines, resulting in eosinophilic accumulation in lungs and production of toxic eosinophilic products. ${ }^{5}$

To our knowledge, there are no specific agreed diagnostic criteria for idiopathic CEP. Diagnosis is usually based on the 

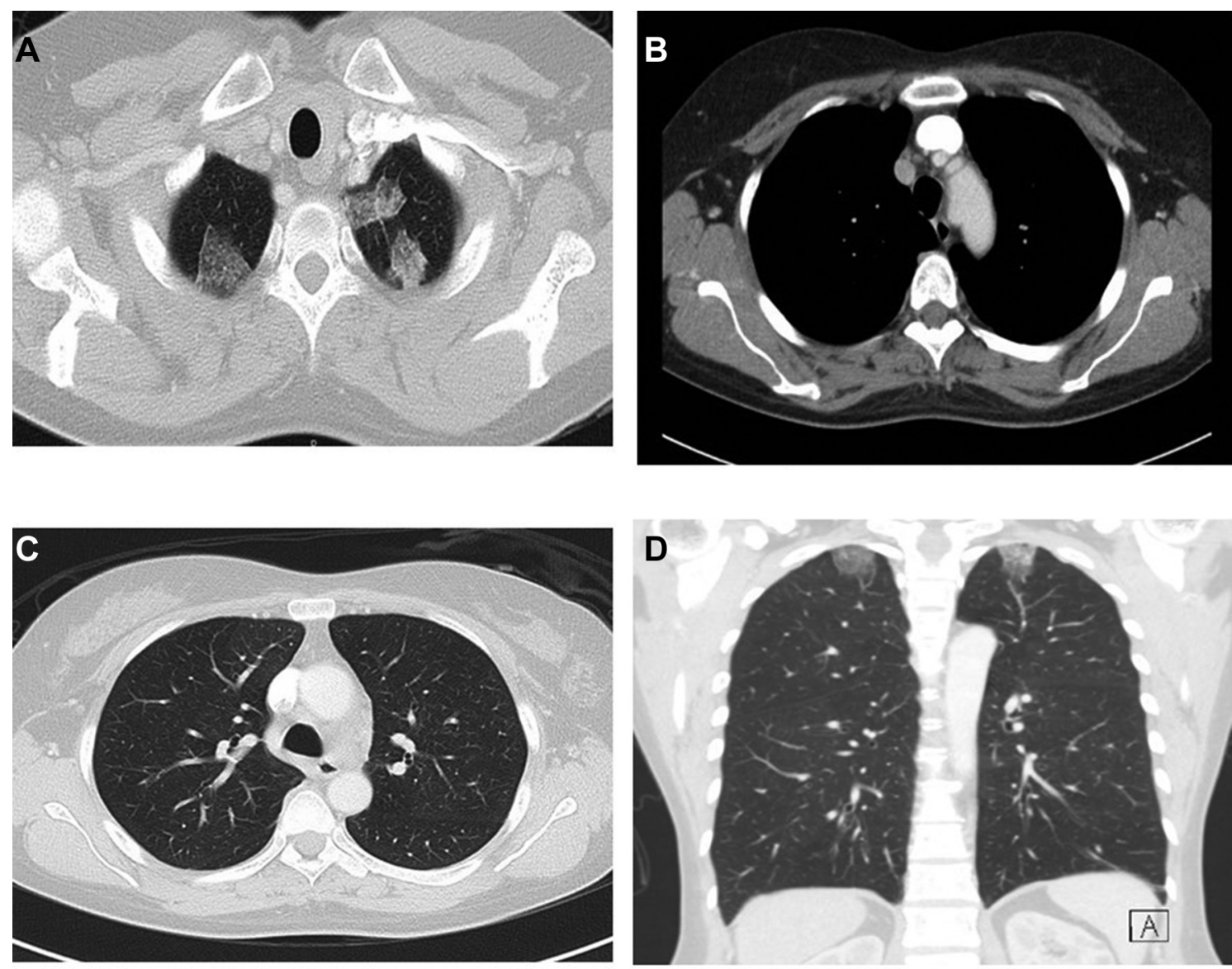

Figure 2 (A) Contrasted CT of the chest in the axial plane showing bilateral apical ground glass changes with thickening of the interlobular septa at the apices of both lungs, more marked over the apical segment of the left upper lobe. (B)Contrasted CT of the chest in the axial plane showing absence of ground glass changes and septal thickening in the midlung. (C)Contrasted CT of the chest in the axial plane (soft tissue window) showing lack of adenopathy. (D) Contrasted CT of the chest in the coronal plane showing upper lobe predominance of ground glass opacities.

association of: respiratory symptoms of more than 2 weeks' duration, alveolar and/or blood eosinophilia (BAL differential eosinophil count $>25 \%$, but typically $\geq 40 \%$, blood

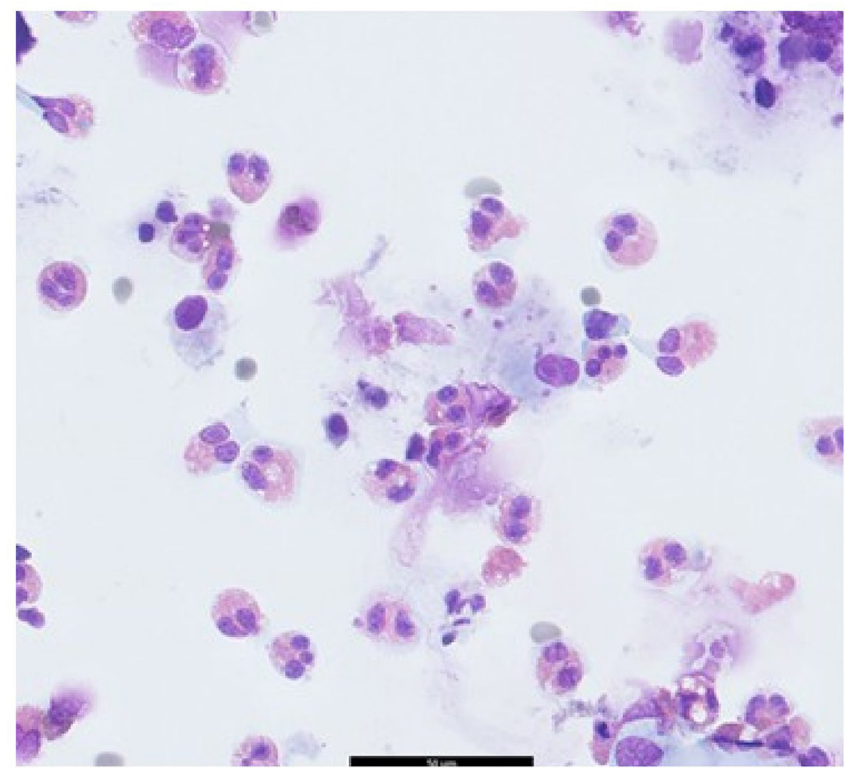

Figure 3 Bronchoalveolar lavage at high magnification $(\times 40)$ showing predominantly eosinophilic yield (Diff-Quick stain). eosinophilia $\geq 1000 / \mu \mathrm{L}$ ), pulmonary infiltrates in a predominantly peripheral pattern on chest imaging, as well as exclusion of any known causes of eosinophilia. ${ }^{6}$ CEP typically affects patients in their 30 s to 40 s, and a history of atopy is found in up to $60 \%$ of these cases. ${ }^{7}$ The onset of disease is typically insidious and a mean time to diagnosis from presentation can take up to 5 months. ${ }^{8}$ Common presenting symptoms include cough, dyspnoea, fever, night sweats and weight loss. Asthma may be present in up to $50 \%$ of patients and may occur before, during or after the diagnosis of CEP. ${ }^{7}$ No laboratory studies are specific for CEP. Peripheral blood eosinophils are typically $>1000 / \mu \mathrm{L}$, accompanied by a high erythrocyte sedimentation rate and C reactive protein. ${ }^{9}{ }^{10}$ Serum $\mathrm{IgE}$ is elevated in nearly $50 \%$ (mean of $1214 \mathrm{ng} / \mathrm{mL}$ ). ${ }^{11}$ Spirometry in CEP may be obstructive,

Table 1 Table showing differential cell counts in bronchoalveolar lavage fluid

\begin{tabular}{lcc}
\hline Cell type & Absolute cell count & Percentage \\
\hline Macrophages & 41.5 & 10.4 \\
Lymphocytes & 7 & 1.8 \\
Neutrophils & 9.5 & 2.4 \\
Eosinophils & 333.5 & 83.3 \\
Mast cells & 0 & 0 \\
\hline Ciliated epithelial cells & 2 & 0.5 \\
Squamous epithelial cells & 6.5 & 1.6 \\
\hline
\end{tabular}



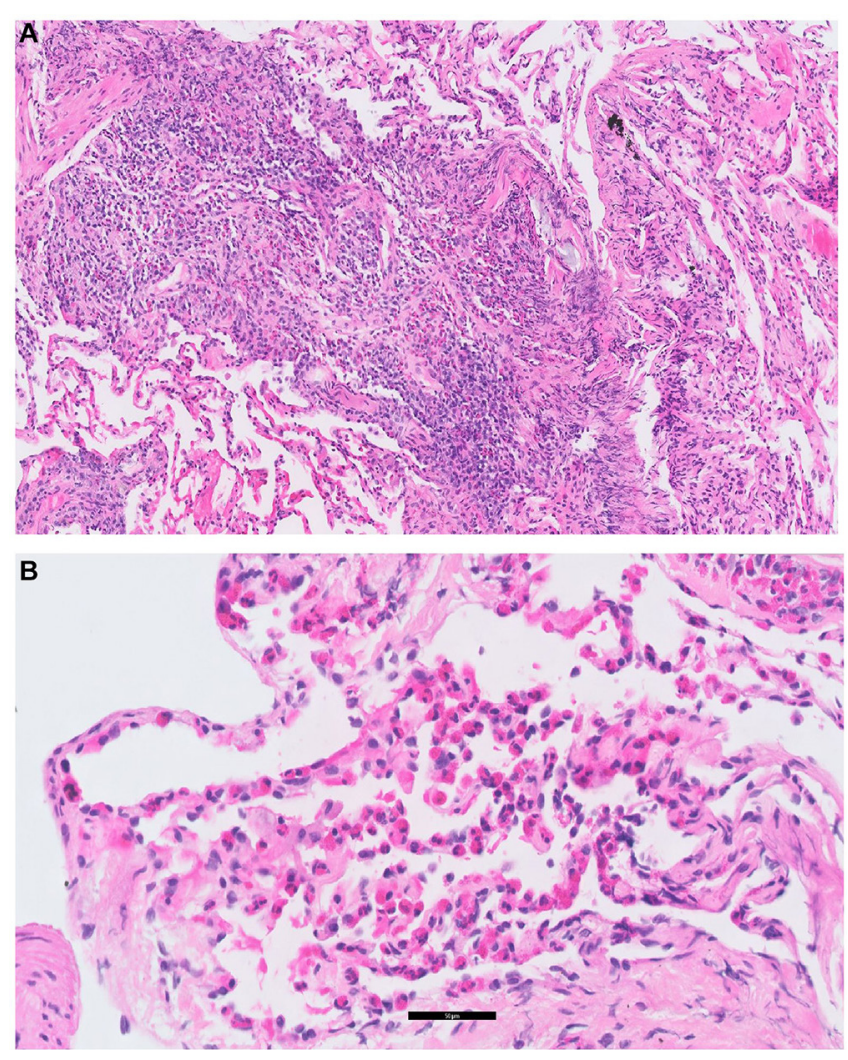

Figure 4 Transbronchial lung biopsy under low power $(\times 10)$ magnification with H\&E stain showing large collections of eosinophils predominantly in the interstitium. (B) Transbronchial lung biopsy under high power $(\times 40)$ magnification with H\&E stain showing large collections of eosinophils predominantly in the alveolar spaces and interstitium.

restrictive or normal. A case series of 19 patients revealed an obstructive pattern in 21\%, a restrictive pattern in $47 \%$ and a normal pattern in $32 \% .{ }^{8}$ Diffusion studies usually reveal reduced carbon monoxide transfer factor and carbon monoxide transfer coefficient. ${ }^{9}$ Radiological findings typically show bilateral peripheral, non-segmental, consolidative opacities described as the 'photographic negative' of pulmonary oedema. However, the 'photographic negative' pattern on the chest radiograph is present in only one-fourth of patients and is not specific for CEP. Bronchoscopy in CEP typically shows BAL differential eosinophil counts of $>25 \% .{ }^{12}$ Only rarely is eosinophilia absent in BAL, in which case lung biopsies are performed. Otherwise, lung biopsy is rarely required to make a diagnosis of CEP. If lung biopsies are performed, transbronchial lung biopsy is usually sufficient and surgical lung biopsies are rarely required. Also, bone marrow biopsy may not necessary in the initial workup of the typical case of chronic eosinophilic pneumonia but may considered should the eosinophilia not respond to treatment with steroids.

The mainstay of treatment in CEP includes the use of steroids. However, to the best of our knowledge, there has been no consensus recommendation on the duration and dose of steroid therapy. In some studies, acutely unwell patients with rapidly progressive disease received 3 to 5 days of high-dose steroids (intravenous methylprednisolone $250 \mathrm{mg}$ every 6 hours), after which they were converted to oral prednisolone once they are stabilised. All other patients were started on oral prednisolone, typically at a dose of $0.5 \mathrm{mg} / \mathrm{kg} / \mathrm{day}^{13}$ and tailed down after 2 weeks of treatment. Clinical improvement following steroid administration is typically dramatic, with response seen within 48 hours. $^{9}$ An alternative diagnosis should be sought if patients do not improve quickly with steroids. Clinical response can be measured by improvement in symptoms, decline in pulmonary or peripheral blood eosinophilia, marked reduction or clearing of radiographic abnormalities, as well as physiological improvement on spirometry or diffusion coefficient. ${ }^{14}$

Both symptomatic and radiographic relapse is common in CEP after cessation of therapy or during tailing of steroid doses. ${ }^{9}$ Time of relapse can occur any time from months to years after the initial presentation. Management of relapse includes increasing steroid dose up to $0.5 \mathrm{mg} / \mathrm{kg} /$ day for the next 1 to 2 weeks. Although the total dose and length of treatment may vary among patients, one study showed that up to three quarters of patients require prolonged steroid therapy, with a mean duration of 19 months. ${ }^{15}$ In the study by Marchand et al, up to $69 \%$ of patient were still on oral corticosteroid therapy over the mean follow-up period of 6.2 years. ${ }^{9}$ Some studies also recommend the use of inhaled corticosteroids to lower the rate of CEP relapse. ${ }^{714}$

\section{Learning points}

- Asthma is commonly associated with peripheral blood eosinophilia. However, markedly increased levels are not common in allergic asthma and a high index of suspicion for another cause is required especially if patients do not respond to inhaled corticosteroid therapy.

- Chronic eosinophilic pneumonia (CEP) should be considered in a patient with asthma-like symptoms with blood and pulmonary eosinophilia.

- Patients with CEP show dramatic response to systemic steroid therapy, though relapses during tailing of doses are common.

Contributors ST prepared the manuscript, with intellectual input from AT, KLT and AH. AT prepared the histopathology slides for the article. ST accepts responsibility for the accuracy of the information presented in this manuscript. All correspondence should be made directly to her.

Funding The authors have not declared a specific grant for this research from any funding agency in the public, commercial or not-for-profit sectors.

Competing interests None declared.

\section{Patient consent Obtained.}

Provenance and peer review Not commissioned; externally peer reviewed.

Open Access This is an Open Access article distributed in accordance with the Creative Commons Attribution Non Commercial (CC BY-NC 4.0) license, which permits others to distribute, remix, adapt, build upon this work non-commercially, and license their derivative works on different terms, provided the original work is properly cited and the use is non-commercial. See: http://creativecommons.org/ licenses/by-nc/4.0/

(C) BMJ Publishing Group Ltd (unless otherwise stated in the text of the article) 2018. All rights reserved. No commercial use is permitted unless otherwise expressly granted.

\section{REFERENCES}

1 Allen JN, Davis WB. Eosinophilic lung diseases. Am J Respir Crit Care Med 1994; 150:1423-38.

2 Bain GA, Flower CD. Pulmonary eosinophilia. Eur J Radiol 1996;23:3-8.

3 Umeki S. Reevaluation of eosinophilic pneumonia and its diagnostic criteria. Arch Intern Med 1992;152:1913-9.

4 Carrington CB, Addington WW, Goff AM, et al. Chronic eosinophilic pneumonia. N Engl J Med 1969;280:787-98.

5 Alam M, Burki NK. Chronic eosinophilic pneumonia: a review. South Med J 2007;100:49-53

6 Marchand E, Cordier JF. Idiopathic chronic eosinophilic pneumonia. Semin Respir Crit Care Med 2006;27:134-41. 
7 Marchand E, Etienne-Mastroianni B, Chanez P, et al. Idiopathic chronic eosinophilic pneumonia and asthma: how do they influence each other? Eur Respir J 2003:22:8-13.

8 Durieu J, Wallaert B, Tonnel AB. Long-term follow-up of pulmonary function in chronic eosinophilic pneumonia. Groupe d'Etude en Pathologie Interstitielle de la Société de Pathologie Thoracique du Nord. Eur Respir J 1997;10:286.

9 Marchand E, Reynaud-Gaubert M, Lauque D, et al. Idiopathic chronic eosinophilic pneumonia. A clinical and follow-up study of 62 cases. The Groupe d'Etudes et de Recherche sur les Maladies "Orphelines" Pulmonaires (GERM"O"P). Medicine 1998;77:299.

10 Marchand E, Cordier JF. Idiopathic chronic eosinophilic pneumonia. Orphanet J Rare Dis 2006;1:11
11 Matsuse H, Shimoda T, Fukushima C, et al. Diagnostic problems in chronic eosinophilic pneumonia. J Int Med Res 1997:25:196-201.

12 Meyer KC, Raghu G, Baughman RP, et al. An official American Thoracic Society clinical practice guideline: the clinical utility of bronchoalveolar lavage cellular analysis in interstitial lung disease. Am J Respir Crit Care Med 2012;185(9):1004-14.

13 Samman YS, Wali SO, Abdelaal MA, et al. Chronic eosinophilic pneumonia presenting with recurrent massive bilateral pleural effusion : case report. Chest 2001:119:968-70.

14 Naughton M, Fahy J, FitzGerald MX, et al. Chronic eosinophilic pneumonia. A longterm follow-up of 12 patients. Chest 1993;103:162-5.

15 Jederlinic PJ, Sicilian L, Gaensler EA. Chronic eosinophilic pneumonia. A report of 19 cases and a review of the literature. Medicine 1988;67:154-

Copyright 2018 BMJ Publishing Group. All rights reserved. For permission to reuse any of this content visit http://group.bmj.com/group/rights-licensing/permissions.

BMJ Case Report Fellows may re-use this article for personal use and teaching without any further permission.

Become a Fellow of BMJ Case Reports today and you can:

- Submit as many cases as you like

- Enjoy fast sympathetic peer review and rapid publication of accepted articles

- Access all the published articles

- Re-use any of the published material for personal use and teaching without further permission

For information on Institutional Fellowships contact consortiasales@bmjgroup.com

Visit casereports.bmj.com for more articles like this and to become a Fellow 